\title{
Antioxidant Activity of Diphenylpropionamide Derivatives: Synthesis, Biological Evaluation and Computational Analysis
}

\author{
Paolo Urbani ${ }^{1}$, Anna Ramunno ${ }^{1}$, Rosanna Filosa ${ }^{1}$, Aldo Pinto ${ }^{1}$, Ada Popolo ${ }^{1}$, Erminia \\ Bianchino ${ }^{1}$, Stefano Piotto ${ }^{1}$, Carmela Saturnino ${ }^{1}$, Rocco De Prisco ${ }^{2}$, Barbara Nicolaus ${ }^{2}$ and \\ Giuseppina Tommonaro ${ }^{2, *}$
}

${ }^{1}$ Department of Pharmaceutical Sciences, University of Salerno,Via Ponte don Melillo, 84084 Fisciano, (SA) Italy; E-mails: purbani@unisa.it (P. Urbani); aramunno@unisa.it (A. Ramunno); rfilosa@unisa.it (R. Filosa); pintoal@unisa.it (A. Pinto); apopolo@unisa.it (A. Popolo); ebianchino@unisa.it (E. Bianchino); piotto@unisa.it (S. Piotto); saturnino@unisa.it (C. Saturnino)

2 Institute of Biomolecular Chemistry-CNR, Via Campi Flegrei 34, 80078 Pozzuoli, (NA) Italy; E-mails: roccodeprisco1@virgilio.it (R. De Prisco); bnicolaus@icmib.na.cnr.it (B. Nicolaus)

* Author to whom correspondence should be addressed; E-mail: gtommonaro@icmib.na.cnr.it; Phone: +39-81-8675190; Fax: +39-81-8041770

Received: 14 February 2008; in revised form: 4 March 2008 / Accepted: 25 March 2008 / Published: 28 March 2008

\begin{abstract}
We report the synthesis, antioxidant and antiproliferative activity and a QSAR analysis of synthetic diphenylpropionamide derivatives. Synthesis of these compounds was achieved by direct condensation of 2,2- and 3,3-diphenylpropionic acid and appropriate amines using 1-propylphoshonic acid cyclic anhydride (PPAA) as catalyst. Compound structures were elucidated by NMR analysis and their melting points were measured. The in vitro antioxidant activity of these compounds was tested by evaluating the amount of scavenged ABTS radical and estimating ROS and NO production in LPS stimulated J774.A1 macrophages. All compounds were tested for their effect on viability of cells and results demonstrated that they are not toxic towards the cell lines used. The cytotoxic activity of all compounds was evaluated by a Brine Shrimp Test.
\end{abstract}

Keywords: Diphenylpropionamide derivatives, antioxidant activity, brine shrimp test, antiproliferative activity, QSAR analysis. 


\section{Introduction}

Antioxidant activity (AOA) is a very important parameter used to characterize different plant materials. This activity is related with compounds capable of protecting a biological system against the potential harmful effects of oxidative processes. Antioxidants have received increased attention in the last years from nutritionists and medical researchers for their potential activities in the prevention of several degenerative diseases such as cancer and cardiovascular disorder, as well as aging [1-4]. In recent years, several works have been published on structure-activities analysis on compounds with antioxidant activities. In the works of Rasulev [5] and Amic [6] on flavonoids, it was shown that quantum-chemical descriptors are very important in the description of their activities.

Various biological activities have been attributed to amides and their derivatives, including pharmacological roles, prevention and treatment of tissue damage, involvement in inflammatory sites, the treatment of psoriasis and ulcerative colitis, etc. [7]. The ready access to plant material, the abundance of natural products therein, as well the ease of extraction make amides useful starting materials for the preparation of potentially bioactive compounds [8].

On the other hand, are few reports on antioxidant activity of synthetic compounds [9-11]. Consequently the synthesis of new active derivatives with potential applications in this area and prepared by simple chemical procedures should be of increasing interest. In the present study we report the chemical synthesis of some compounds structurally related to diphenylpropionamide derivatives, their biological activity and a computational QSAR analysis.

\section{Results and Discussion}

As shown in Scheme 1, amides 1-11 were obtained by direct condensation of 2,2- and 3,3diphenylpropionic acid and appropriate amines using $n$-propylphosphonic acid anhydride (PPAA) as catalyst [12]. Table 1 shows the structures of the compounds tested for their antioxidant activity, the latter being expressed both as percent reduction of the absorbance due to the ABTS radical and as T.E.A.C. $\left(\right.$ Trolox ${ }^{\circledR}$ Equivalent Antioxidant Capacity, $\mu \mathrm{M}$ ) values. In this Table the biological activity (expressed as $\mathrm{LD}_{50}$ in $\mathrm{ppm}$ ) of the compounds in the brine shrimp test is also reported.

Scheme 1. Synthesis of compounds 1-11.

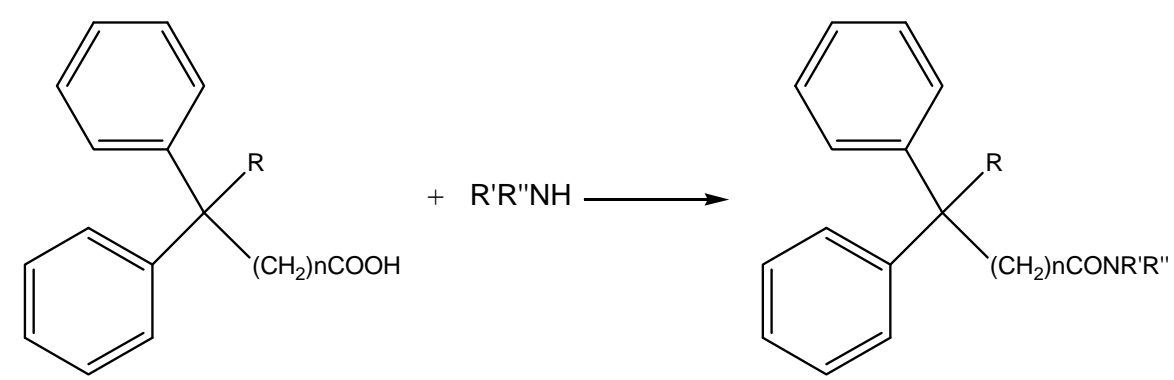

$$
\mathrm{R}=\mathrm{H}, \mathrm{CH}_{3} ; \mathrm{R}^{\mathrm{I}}=\text { amines of table } 1 ; \mathrm{n}=0,1,2
$$

Reagents and conditions: PPAA, TEA, dichloromethane, RT overnight 
The maximum antioxidant activity was exhibited by compounds 3 and 8 (78.19\% and $71.4 \%$, respectively), having a morpholine ring as substituent R". Also compounds $\mathbf{4}$ and 9, with a methoxybenzylmethyl group as substituent R", showed a moderate antioxidant activity $(41.8 \%$ and $33.93 \%$, respectively). Among the tested compounds, the samples 3, 4 and $\mathbf{8}$, showing the best antioxidative activity, were also assayed by evaluation of ROS and NO production in the murine macrophage cell line J774.A1 stimulated with LPS. One hour incubation with compounds $\mathbf{3}, \mathbf{4}$ or 8 (0.01-1 $\mu \mathrm{M})$ resulted in a concentration-dependent ROS reduction in J774.A1 (Figure 1). Furthermore, incubation with compounds 3,4 or $\mathbf{8}(0.01-1 \mu \mathrm{M})$ concentration-dependently reduced nitrite production in J774.A1 at $24 \mathrm{~h}$ (Figure 2).

Figure 1. Effect of compounds 3, 4 and $\mathbf{8}$ on ROS production in J774.A1 macrophages.

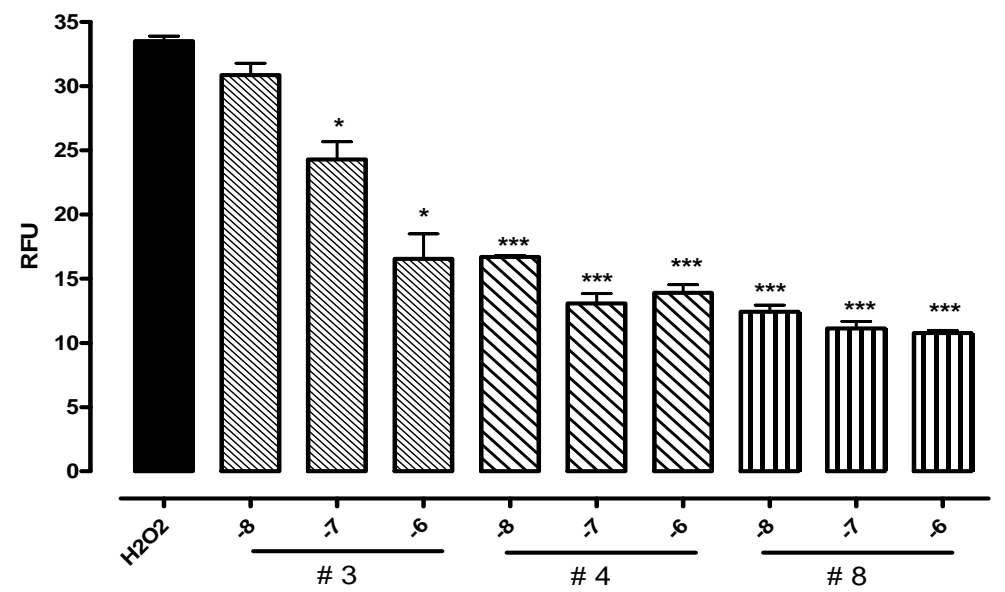

ROS reaction was determined by measuring the converting reaction of the DCFH2 to DCF and ROS were expressed in Relative Fluorescence Units (RFU). $* \mathrm{P}<0.05$ vs $\mathrm{H}_{2} \mathrm{O}_{2} ; * * * \mathrm{P}<0.001$ vs $\mathrm{H}_{2} \mathrm{O}_{2}$.

Figure 2. Effect of compounds 3, 4 and $\mathbf{8}$ to LPS-stimulated macrophages J774.A1 on NO release.

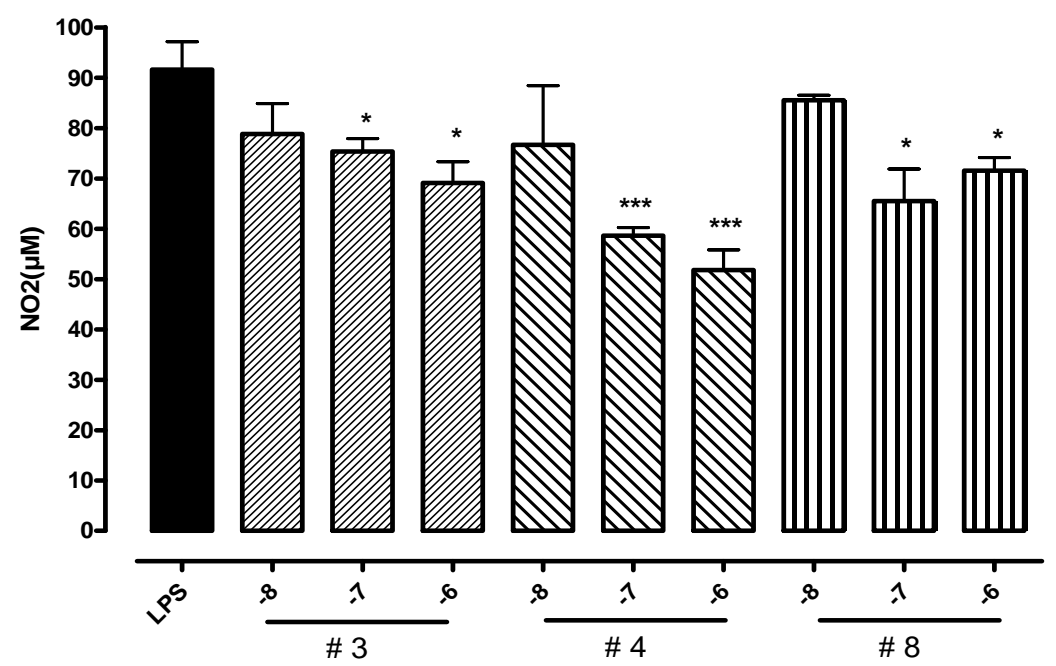

$\mathrm{NO}$ release was evaluated as nitrites + nitrates $\left(\mathrm{NO}_{2}^{-} ; \mathrm{NO}_{3}^{-}\right)$in incubation medium. $* \mathrm{P}<0.05$ vs LPS; $* * \mathrm{P}<0.01$ vs LPS and $* * * \mathrm{P}<0.001$ vs LPS 
The brine shrimp lethality bioassay is an efficient, rapid and inexpensive test developed as prescreening to evaluate biological activities of natural or synthetic compounds. This test is often used as a guide for fractionating extracts from natural sources [13-18]. This bioassay has a good correlation with cytotoxic activity in some human solid tumours and other biological activities [19,20]. In Table 1 we report the biological activity in the brine shrimp assay of the samples, expressed as $\mathrm{LD}_{50}$ (in $\mathrm{ppm}$ ). All samples showed good activity in the brine shrimp test, in particular compound 10, which showed a most interesting value of $1.38 \mathrm{ppm}\left(\mathrm{LD}_{50}\right)$ These results suggest that these compounds could have a potential specific biological activity (anti-inflammatory or anti-viral activities for example) and further analysis are underway to prove this hypothesis.

Table 1. Biological activities of samples 1-11.

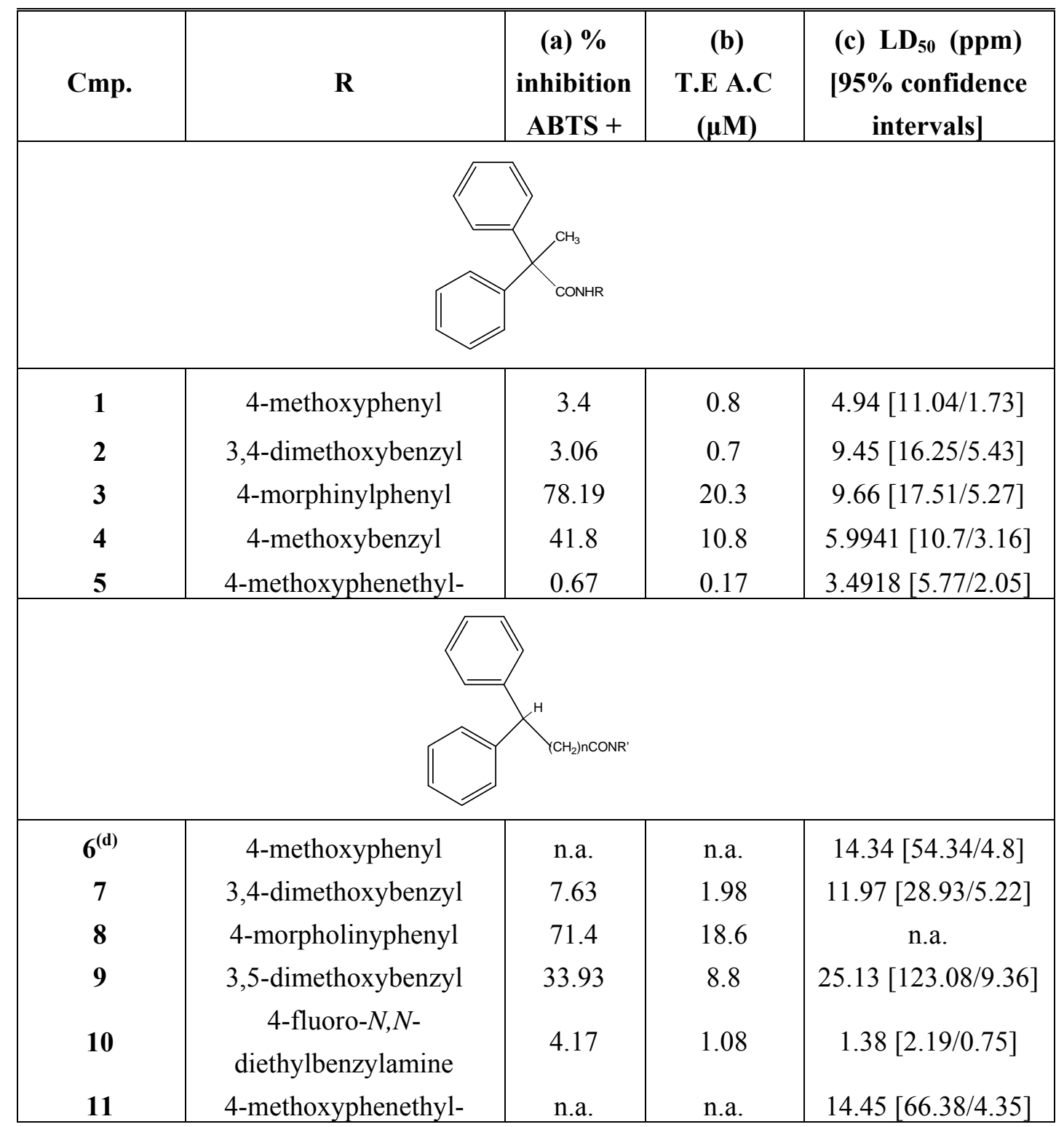

(a) Percentage of the absorbance of the uninhibited radical cation solution obtained by using ABTS method. (b) Antioxidant activity of samples expressed as T.E.A.C $(\mu \mathrm{M})$. (c) Biological activity in brine shrimps assay of samples. In square parenthesis are shown the values of $95 \%$ confidence intervals; n.a. no activity, (d) $\mathrm{n}: 1 . \mathrm{R}=$ amines listed in table; $\mathrm{n}=0,1,2$ 
We have also performed an extended computational and Quantitative-Structure Activity Relationship (QSAR) investigation on these molecules to define the molecular features required for high antioxidant activity. For all the molecules listed in Table 1, we have calculated more than 500 molecular descriptors, covering topological, structural, and electronic properties. None of the explored parameters showed a correlation when considered singularly with the AOA. Therefore we performed a QSAR investigation via genetic functions (GF).

One of the main advantages of GF analysis is the production of multiple models. In all the models generated, crucial importance is given to electronic descriptors. We generated a total of 100 QSAR equations that consist of one to four descriptors among the QSAR random models. Among the models, the one with the strongest predictive power of the antioxidant activity (AOA) was the following:

$$
A O A=-6.32 D i p Z+13.52 \operatorname{InvEn^{2}}-13.76
$$

The model described by eq. 1 was obtained with the training sets 4 to 11. The molecular descriptors of eq. 1 are described in the Computational Analysis section. Applying the "test set method" strategy we generated models using only eight out of 11 molecules. All the models obtained as outcome of the different choice of the training set, have been tested against the three molecules left out. The data shown in the last two columns of Table 2 have been obtained with the model generated with basis set of molecules from 4 to 11.

Table 2. Data obtained with the model generated with basis set of molecules from $\mathbf{1}$ to 11.

\begin{tabular}{|c|c|c|c|c|c|}
\hline Molecule & Experimental AOA & Dipole $\mathrm{z}^{\mathrm{a}}$ & Inversion energy $^{\mathbf{b}}$ & Predicted AOA & Residual AOA \\
\hline 6 & 0.000 & 1.98 & 1.49 & 3.74 & 3.74 \\
\hline 11 & 0.000 & 2.057 & 1.54 & 5.30 & 5.30 \\
\hline 5 & 0.670 & 2.22 & 1.34 & -3.51 & -4.18 \\
\hline 2 & 3.060 & 0.72 & 1.21 & 1.48 & -1.58 \\
\hline 1 & 3.400 & -0.365 & 1.11 & 5.20 & 1.80 \\
\hline 10 & 4.170 & -0.816 & 1.14 & 8.97 & 4.80 \\
\hline 7 & 7.630 & 0.522 & 1.48 & 12.56 & 4.93 \\
\hline 9 & 33.930 & -1.75 & 1.47 & 26.52 & -7.41 \\
\hline 4 & 41.800 & 1.84 & 1.58 & 8.36 & -33.44 \\
\hline 8 & 71.400 & 1.57 & 2.65 & 71.26 & -0.14 \\
\hline 3 & 78.200 & 0.265 & 2.63 & 78.08 & -0.12 \\
\hline
\end{tabular}

In Figure 3 the comparison between calculated and experimental values is shown. The magnitudes of dipole moments and inversion energy provide an essential contribution to the antioxidant activity. Specifically, the dipole moment inversely correlates with the AOA, whereas the inversion energy directly correlates with it. The deviation of molecule 4 seems to be due to the high dipole moment together with low inversion energy. In fact, inversion energy, and consequently the molecular rigidity, has a prominent role to determine high antioxidant activities. 
Figure 3. Comparison of experimental and calculated values of antioxidant activity (AOA) using the model from eq. 1.

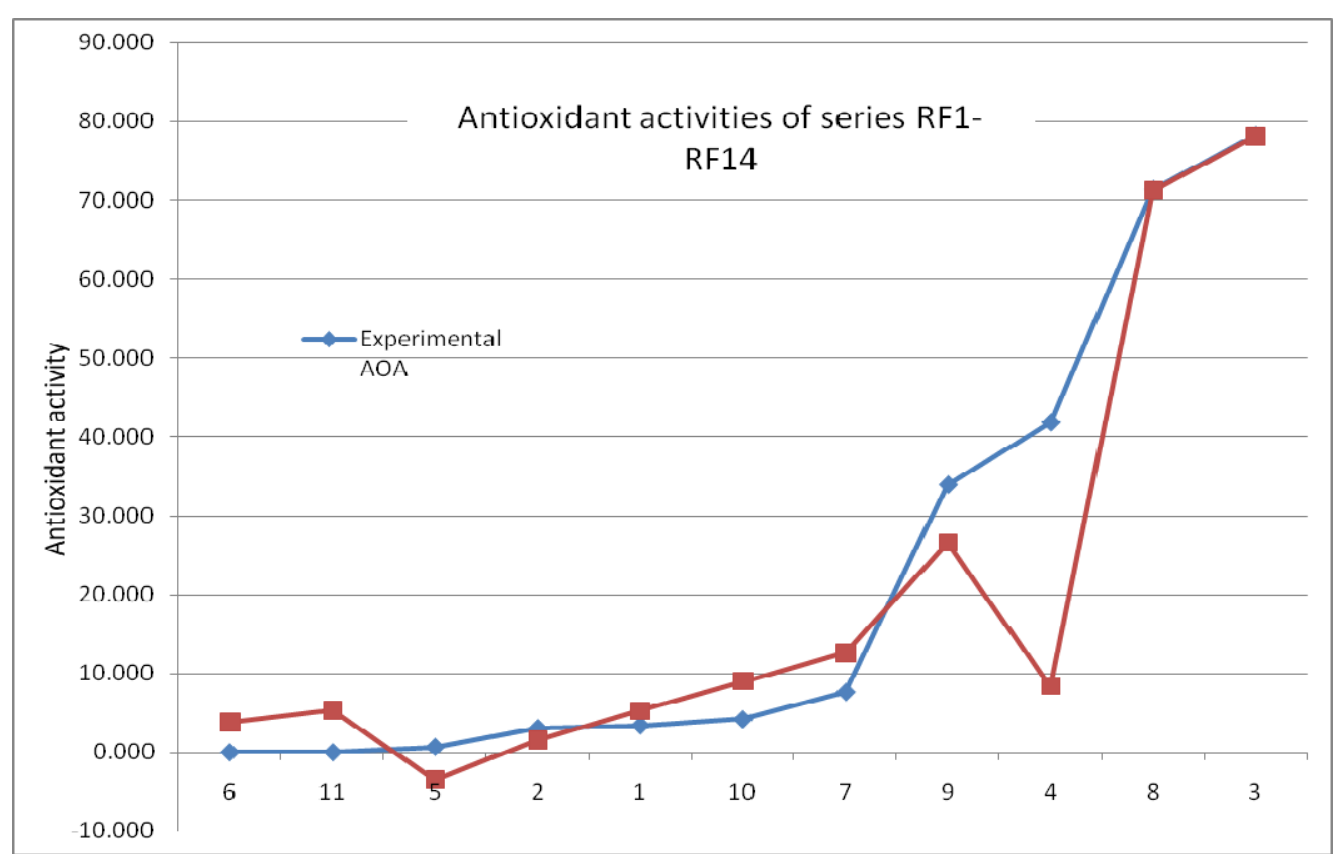

Cell viability was assessed by a MTT-formazan salt conversion assay, and as reported in Table 3, these compounds are not cytotoxic on cellular lines used. Compounds $\mathbf{3}$ and $\mathbf{8}$, having a morpholine

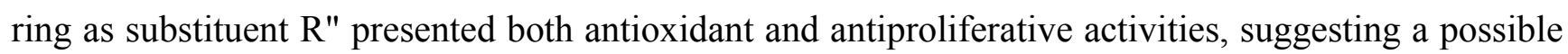
structure-activity relationship.

Table 3. Antiproliferative activity of samples 1-11.

\begin{tabular}{|c|c|c|c|}
\hline \multicolumn{4}{|c|}{ In Vitro Antiproliferative Activity of Compounds } \\
\hline & \multicolumn{3}{|c|}{ IC $_{50}$ (5\% confidence limits) } \\
\hline $\mathrm{cmp}$ & J774.A1 & HEK-293 & WEHI-164 \\
\hline $\mathbf{3}$ & $8.4(6.7-0.11)$ & $3.4(2.2-4.4)$ & $5.4(4.6-6.4)$ \\
\hline $\mathbf{4}$ & $9.7(1.7-14)$ & $>10$ & $>10$ \\
\hline $\mathbf{8}$ & $0.14(0.12-0.17)$ & $5.7(2.3-14)$ & $14(13-16)$ \\
\hline
\end{tabular}

The $\mathrm{IC}_{50}$, express as $\mathrm{mmoli} / \mathrm{L}$, value is the concentration of compound that affords a $50 \%$ reduction in cell growth (after a $24 \mathrm{~h}$ incubation). J774.A1 = murine monocyte/macrophage cell lines. HEK-293 = human epithelial kidney cell lines. WEHI-164 = murine fibrosarcoma cell lines.

\section{Conclusions}

Results show that these diphenylpropionamide derivatives, obtained by simple and rapid chemical synthesis, had interesting biological activities and that none of the compounds are toxic. Moreover a QSAR analysis carried out using genetic functions approximation allowed us to build a chemical 
model (eq. 1) where electronics descriptors were of supreme importance. The statistics of the model was remarkably good, with the exception of molecule 4 , where the model predicted no antioxidant activity and the experimental measurements attribute to that compound a modest activity.

\section{Experimental}

\section{General}

Analytical grade methanol, dichloromethane, diethyl ether and ethanol were obtained from Carlo Erba (Italy). Methanol and dichloromethane (HPLC grade) from Merck (Darmstadt, Germany) were used. 2,2'-Azino-bis-(3-ethylbenzothiazoline-6-sulfonic acid) (ABTS) as its crystalline diammonium salt was purchased from Fluka. 6-Hydroxy-2,5,7,8-tetramethyl chroman-2-carboxylic acid (Trolox ${ }^{\circledR}$ ) was purchased from Aldrich and potassium persulfate $\left(\mathrm{K}_{2} \mathrm{~S}_{2} \mathrm{O}_{8}\right)$ was purchased from Sigma Chemical Co. (Italy). Spectrophotometric measurements were recorded at controlled room temperature $\left(25{ }^{\circ} \mathrm{C}\right)$ with a Varian DMS 90 UV-VIS spectrophotometer. Flash column chromatography was carried out using silica gel $60(0.040-0.063 \mathrm{~mm}$, Merck). Melting points were determined on a Gallenkamp hot stage apparatus and are uncorrected. ${ }^{1} \mathrm{H}-\mathrm{NMR}$ spectra were recorded on a Bruker ARX $300 \mathrm{MHz}$ spectrometer. CAS Registry numbers: $N$-(4-methoxyphenyl)-2,2-diphenylpropionamide (1): 353466 46-3; $\quad N$-[(4-methoxyphenyl)methyl]-3,3-diphenylpropionamide $\quad(6): \quad 331864-56-3) ; \quad N-[(3,4$ dimethoxyphenyl)methyl]-3,3-diphenylpropionamide (7): 895679-31-9; $N$-[4-(4-morpholinyl)phenyl]3,3-diphenylpropionamide (8): 805273-67-0); 1-(4-fluorophenyl)-4-(1-oxo-3,3-diphenylpropyl)piperazine (10): 348611-42-7; $\quad N$-[2-(4-methoxyphenyl)ethyl]-3,3-diphenylpropionamide $\quad$ (11): 303137-57-7.

\section{General procedure for the synthesis of compounds 1-11}

Triethylamine (4 eq) was added to a solution of PPAA (2 eq), acid (1 eq), and amine (1.2 eq) in dichloromethane $(5 \mathrm{~mL})$, and resulting reaction mixture was stirred overnight at room temperature. The solvent was removed under reduced pressure and the residue was purified by flash chromatography (silica gel) using $n$-hexane/AcOEt (1:1) as eluent.

$\mathrm{N}$-[(3,4-dimethoxyphenyl) methyl]-2,2-diphenyl propionamide (2). White solid $(40 \%) ; \mathrm{mp}: 70{ }^{\circ} \mathrm{C} ;{ }^{1} \mathrm{H}$ NMR $\left(\mathrm{CDCl}_{3}\right): \delta 2.08\left(\mathrm{~s}, 3 \mathrm{H}, \mathrm{CH}_{3}\right) ; 3.83\left(\mathrm{~s}, 3 \mathrm{H}, \mathrm{OCH}_{3}\right) ; 3.88\left(\mathrm{~s}, 3 \mathrm{H}, \mathrm{OCH}_{3}\right) ; 4.43\left(\mathrm{~d}, 2 \mathrm{H}, \mathrm{CH}_{2}\right) ; 5.79$ (bs, 1H, NH); 6.71 (m, 2H, HAr); 6.79 (m, 1H, HAr); 7.26-7.45 (m, 10H, HAr).

$N$-[4-(4-morpholinyl)phenyl]-2,2-diphenyl propionamide (3). White solid (55\%); mp: $140{ }^{\circ} \mathrm{C} ;{ }^{1} \mathrm{H}$ NMR $\left(\mathrm{CDCl}_{3}\right) \delta 2.09$ (s, 3H, $\left.\mathrm{CH}_{3}\right) ; 3.13$ (m, 4H, H morpholine); 3.89 (m, 4H, H morpholine), 6.89 (m, 2H, HAr), 7.10 (bs, 1H, NH), 7.30-7.40 (m, 12H, HAr).

$N$-[(4-methoxyphenyl) methyl]-2,2-diphenyl propionamide (4). White solid (65\%); mp: $85{ }^{\circ} \mathrm{C}$; ${ }^{1} \mathrm{H}$ NMR $\left(\mathrm{CDCl}_{3}\right) \delta 2.08\left(\mathrm{~s}, 3 \mathrm{H}, \mathrm{CH}_{3}\right) ; 3.81\left(\mathrm{~s}, 3 \mathrm{H}, \mathrm{OCH}_{3}\right) ; 4.42\left(\mathrm{~d}, 2 \mathrm{H}, \mathrm{CH}_{2}\right), 5.75(\mathrm{bs}, 1 \mathrm{H}, \mathrm{NH}) ; 6.84$ (m, 2H, HAr); 7.09 (m, 2H, HAr); 7.25-7.34 (m, 10H, HAr). 
$\mathrm{N}$-[(4-methoxyphenyl)ethyl]-2,2-diphenyl propionamide (5). White solid (60\%); mp: $84{ }^{\circ} \mathrm{C} ;{ }^{1} \mathrm{H}-\mathrm{NMR}$ $\left(\mathrm{CDCl}_{3}\right) \delta 2.05\left(\mathrm{~s}, 3 \mathrm{H}, \mathrm{CH}_{3}\right) ; 2.70\left(\mathrm{t}, 2 \mathrm{H}, \mathrm{CH}_{2}\right) ; 3.53\left(\mathrm{dd}, 2 \mathrm{H}, \mathrm{CH}_{2}\right), 3.81\left(\mathrm{~s}, 3 \mathrm{H}, \mathrm{OCH}_{3}\right), 5.46(\mathrm{bs}, 1 \mathrm{H}$, $\mathrm{NH}) ; 6.78$ (m, 2H, HAr); 6.93 (m, 2H, HAr), .7.15-7.18 (m, 4H, HAr); 7.28-7.32 (m, 6H, HAr).

\section{Antioxidant activity assay by the ABTS method}

The antioxidant activity of compounds is determined by the ABTS + radical cation decolorization assay involving preformed ABTS + radical cation, according to ABTS method as previously described [21,22]. A solution of ABTS $7 \mathrm{mM}$ is obtained and next ABTS + radical cation is obtained by reacting ABTS with potassium persulfate; this mixture is stored in the dark at room temperature for 12-16 hr before use. Before the assay, the mixture is diluted in ethanol at a ratio 1:100 to give an absorbance at $\lambda=734 \mathrm{~nm}$ of $0.70^{ \pm} 0.02$. Trolox ${ }^{\circledR}(1 \mathrm{mg} / \mathrm{mL})$ was used as standard and aliquots of this compound $(0.5$ $\mu \mathrm{L}, 1 \mu \mathrm{L}, 2 \mu \mathrm{L}, 3 \mu \mathrm{L}, 5 \mu \mathrm{L}$ and $10 \mu \mathrm{L})$ are added to ethanolic ABTS $+(1 \mathrm{~mL})$ to give a standard curve to which all data are referred. All compounds are dissolved in dichloromethane at a concentration of $20 \mathrm{mg} / \mathrm{mL}$ and $5 \mu \mathrm{L}$ are added to ethanolic ABTS + to measure absorbance after $1 \mathrm{~min}$. Antioxidant activity measurements were carried out in triplicate and expressed as percentage of the absorbance of the uninhibited radical solution according to the equation:

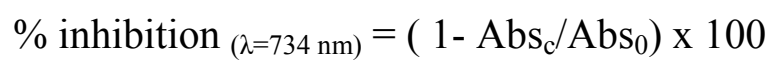

where $\mathrm{Abs}_{0}$ is the absorbance of uninhibited radical solution and $\mathrm{Abs}_{\mathrm{c}}$ is the absorbance measured 1 min after addition of compound to assay. The antioxidant activity of samples is expressed as T.E.A.C. (Trolox ${ }^{\circledR}$ Equivalent Antioxidant Capacity - $\mu \mathrm{M}$ ) [23].

\section{Measurement of reactive oxygen species (ROS)}

The formation of ROS was evaluated by means of the 2',7'-dichlorofluorescein (DCF) probe according to the method described by Hempel et al. [24] and Crow [25]. Briefly, murine macrophage cell line, J774.A1, was seeded at a density of $5 \times 10^{3}$ cells/well into 96 -well plates and allowed to grow for $48 \mathrm{~h}$. After cell adhesion, compounds 3, 4 and $\mathbf{8}(0.01,0.1$ and $1 \mu \mathrm{M})$ were added to the culture medium $6 \mathrm{~h}$ before the fluorescence assay. 2',7'-Dichlorofluorescein-diacetate $\left(\mathrm{H}_{2} \mathrm{DCF}-\mathrm{DA}\right.$, Sigma) was added directly to the growth medium at a final concentration of $5 \mu \mathrm{M}$ and the cells incubated for $1 \mathrm{~h}$ at $37{ }^{\circ} \mathrm{C}$. $\mathrm{H}_{2}$ DCF-DA is a non-fluorescent permeant molecule which diffuses passively into cells; the acetates are then cleaved by intracellular esterases to form $\mathrm{H}_{2} \mathrm{DCF}$ which is thereby trapped within the cell. In the presence of intracellular ROS, $\mathrm{H}_{2} \mathrm{DCF}$ is rapidly oxidized to the highly fluorescent DCF. Then, cells were washed twice with phosphate-buffered saline (PBS), placed in fresh medium and treated with $\mathrm{H}_{2} \mathrm{O}_{2} 3 \mathrm{mM}$ for $30 \mathrm{~min}$. After treatment, cells were washed twice with PBS and the plates placed in a fluorescent microplate reader (LS 55 Luminescence Spectrometer; Perkin Elmer, Beaconsfield, Bucks, UK). Fluorescence was monitored using an excitation wavelength of $490 \mathrm{~nm}$ and an emission wavelength of $520 \mathrm{~nm}$. Results were expressed as Relative Fluorescence Units (RFU). 
Analysis of nitrite

J774.A1 cells were plated to a seeding density of $1.5 \times 10^{6}$ in P60 well plates. After cell adhesion, compounds 3,4 and $\mathbf{8}(0.01,0.1$ and $1 \mu \mathrm{M})$ were added to the culture medium $1 \mathrm{~h}$ before and always simultaneously to LPS $\left(6 \times 10^{3} \mathrm{u} / \mathrm{ml} / 24 \mathrm{~h}\right)$. Nitrite accumulation, an indicator of NO release, was measured in the culture medium by Griess reaction $24 \mathrm{~h}$ after LPS challenge. Briefly, cell culture medium $(100 \mu \mathrm{L})$ was mixed with Griess reagent $[100 \mu \mathrm{L}$, equal volumes of $1 \%(\mathrm{w} / \mathrm{v})$ sulfanilamide in $5 \%(\mathrm{v} / \mathrm{v})$ phosphoric acid with $0.1 \%(\mathrm{w} / \mathrm{v})$ naphthylethylenediamine- $\mathrm{HCl}$ ], incubated at room temperature for $10 \mathrm{~min}$, and then the absorbance at $550 \mathrm{~nm}$ was measured in a Titertek microplate reader (DASIT). Fresh culture medium was used as blank in all the experiments. The amount of nitrite in the samples was calculated from a sodium nitrite standard curve freshly prepared in culture medium. Results are expressed as $\mu \mathrm{mol} \mathrm{NO}$.

\section{Antiproliferative Activity Assay}

Compounds were dissolved in DMSO to obtain $1 \mathrm{M}$ concentration. J774.A1 (murine monocyte/macrophage), WEHI-164 (murine fibrosarcoma), and HEK-293 (human epithelial kidney) cells were grown as reported previously [26]. J774.Al, WEHI-164, and HEK-293 (3.4 × $10^{4}$ cells) were plated on 96-well microtiter plates and allowed to adhere at $37^{\circ} \mathrm{C}$ in $5 \% \mathrm{CO}_{2}$ and $95 \%$ air for $2 \mathrm{~h}$. Thereafter the medium was replaced with $99 \mu \mathrm{L}$ of fresh medium, and a $1 \mu \mathrm{L}$ aliquot of 1:100 serial dilution of each test compound (tested dilutions were $10 \mu \mathrm{M} 100 \mu \mathrm{M}, 1 \mathrm{mM}, 10 \mathrm{mM}$ ) was added and the cells were incubated for $24 \mathrm{~h}$. In vehicle experiments, serial dilutions of DMSO were added. The cell viability was assessed through an MTT conversion assay [27, 28]. The optical density (OD) of each well was measured with a microplate spectrophotometer (Titertek Multiskan MCC/340) equipped with a $620 \mathrm{~nm}$ filter. The viability of each cell line in response to treatment with tested compounds was calculated as \% viability cells $=[($ OD DMSO-OD treatment $) /$ OD DMSO $] \times 100$.

\section{Brine Shrimp Test}

The brine shrimp (Artemia salina) assay was performed in triplicate with appropriate amounts of samples dissolved in DMSO (1\% final volume) to reach final concentrations of 1, 10 and $100 \mathrm{ppm}$, using 10 freshly hatched larvae suspended in artificial sea water $(5 \mathrm{~mL})$ [29]. Briefly, for each dose tested, surviving shrimps were counted after $24 \mathrm{~h}$, and the data analyzed by the Finney program [30], which affords $\mathrm{LD}_{50}$ values with $95 \%$ confidence intervals.

\section{Computational analysis}

To construct a QSAR model the following steps should be followed: (1) assemble a sufficiently large and diverse set of compounds along with their biological activities; (2) select a set of descriptors which is likely to be related to the biological activity of interest; (3) formulate a mathematical equation that reflects the relationship between the biological activity and the chosen descriptors, and finally (4) validate the QSAR model. 
For every molecule listed in Table 1 over 500 molecular descriptors have been calculated and the formulation of the mathematical model was accomplished by means of genetic function analysis (GFA) provided by the program MS Modeling from Accelrys [31]. The GFA approach has a number of important advantages over other techniques: it builds multiple models rather than a single model; it automatically selects which elements are to be used in its basis functions and establishes the appropriate number of basis functions to be used by testing full-size models rather than incrementally building them, and it includes the LOF (lack-of-fit) error measure developed by Friedman that resists over fitting and allows user control over the smoothness of fit. Genetic algorithms are particularly good at searching problem spaces with a large number of dimensions (biological-chemical-physical parameters), as they conduct a very efficient sampling of the possibilities space.

To estimate the predictive power of this QSAR model we employed a strategy called "test set method", which consists of partitioning the initial data into two sets. The first set is used to build a QSAR model and the second one to validate this model. Then the initial data set is randomly divided into two new subsets and the procedure is repeated.

All the molecules were optimized using PM3-NDDO method until the root-mean-square gradient of the force was lower than $0.4 \mathrm{kcal} \mathrm{mol}^{-1} \AA^{-1}$. On the optimized structures, a DFT calculation of the electronic parameters was performed using the Perdew-Wang generalized-gradient approximation [32]. With this method the total dipole, the HOMO energy and the magnitude of the dipole components, i.e. the first 3 terms of eq.1, have been calculated. The breakdown of energy components, including valence, cross terms and $4^{\text {th }}$ term of eq. 1 , the inversion energy (i.e. the inversion component of the valence energy of the system), were calculated using Forcite and the Dreiding forcefield [31] and expressed in $\mathrm{kcal} \mathrm{mol}^{-1}$. In order to evaluate (4) the model we have performed the calculation of the typical set of statistical measurements as reported in Table 4.

Table 4. Calculation of the typical set of statistical measurements.

\begin{tabular}{|l|l|}
\hline Friedman LOF & 164.56185200 \\
\hline R-squared & 0.856 \\
Significant Regression & Yes \\
Significance-of-regression F-value & 101.47 \\
Critical SOR F-value (95\%) & 6.659 \\
Min expt. error for non-significant LOF & 4.262 \\
$(95 \%)$ & \\
\hline
\end{tabular}

The use of the Friedman lack-of-fit (LOF) measure has several advantages over the regular least square error measure. According to Friedman [33], LOF is measured as:

$$
L O F=\frac{S S E}{\left(1-\frac{c+d p}{M}\right)^{2}}
$$

where SSE is the sum of squares of errors, $\mathrm{c}$ is the number of basis functions, other than the constant term, $d$ is a user-defined smoothing parameter, $p$ is the total number of features contained in all the basis functions, and $\mathrm{M}$ is the number of samples in the training set. Unlike the commonly used least 
square measure, the LOF measure cannot always be reduced by adding more terms to the regression model. By limiting the tendency to simply add more terms, the LOF measure resists over fitting better than the SSE measure. An indication of the statistical significance of the model is given by the comparison between the significance of regression F and the critical SOR F value. The comparison is a sign of statistical correlation.

\section{References and Notes}

1. Ames, B.N.; Shigenaga, M.K.; Hagen, T.M. Oxidants, Antioxidants, and the Degenerative Diseases of Aging. Proc. Natl. Acad. Sci. USA 1993, 90, 7915-7922.

2. Hertog, M.G.L.; Feskens, E.J.M.; Hollman, P.C.H.; Katan, M.B.; Kromhout, D. Dietary antioxidant flavonoids and risk of coronary heart disease: the Zutphen Elderly Study. Lancet 1993, 342, 1007-1011.

3. Temple, N.J.; Gladwin, K.K. Fruits, vegetables, and the prevention of cancer: research challenges. Nutrition 2003, 19, 467-470.

4. Peters, U.; Leitzmann, M.F.; Chatterjee, N.; Wang, Y.; Albanes, D.; Gelmann, E. P.; Friesen, M. D.; Riboli, E.; Hayes, R.B. Serum Lycopene, Other Carotenoids, and Prostate Cancer Risk: a Nested Case-Control Study in the Prostate, Lung, Colorectal, and Ovarian Cancer Screening Trial. Cancer Epidemiol. Biomark. Prev. 2007, 16, 962.

5. Rasulev, B.F.; Abdullaev, N.D.; Syrov, V.N.; Leszczynski, J.A. Quantitative Structure-Activity Relationship (QSAR) Study of the Antioxidant Activity of Flavonoids QSAR Comb. Sci. 2005, 24, 1056-1065.

6. Amic, D.; Davidovic-Amic, D.; Beslo, D.; Rastija, V.; Lucic, B.; Trinajstic, N. SAR and QSAR of the Antioxidant Activity of Flavonoids. Curr. Med. Chem. 2007, 14, 827-845.

7. Kim, J.; Wu, D.; Hwang, D.J.; Miller, D.D.; Dalton, J.T. The para substituent of S-3-(phenoxy)2-hydroxy-2-methyl-N-(4-nitro-3-trifluoromethyl-phenyl)-propionamides is a major structural determinant of in vivo disposition and activity of selective androgen receptor modulators. $J$. Pharmacol Exp. Ther. 2005, 315, 230-239.

8. Ribeiro, S.T.; Freire-de-Lima, L.; Previato, J.O.; Mendonça-Previato, L.; Heise, N.; Edilson Freire de Lima, M. Toxic effects of natural piperine and its derivatives on epimastigotes and amastigotes of Trypanosoma cruzi. Bioorg. Med. Chem. Lett. 2004, 14, 3555-3558.

9. Anto, R.J.; Sukumaran, K.; Kuttan, G.; Rao, M.N.A.; Subbaraju, V.; Kuttan, R. Anticancer and antioxidant activity of synthetic chalcones and related compounds. Cancer Lett. 1995, 97, 33-37.

10. Anto, R.J.; Kuttan, G.; Dinesh Babu, K.V.; Rajasekharan, K.N.; Kuttan, R. Anti-tumour and free radical scavenging activity of synthetic curcuminoids. Int. J. Pharm. 1996, 131, 1-7.

11. Iverson, F. Phenolic antioxidants: Health Protection Branch studies on butylated hydroxyanisole. Cancer Lett. 1995, 93, 49-54.

12. Teall, M.; Harrison, T.; Moseley, J.D.; Owens, A.P.; Sadowski, S.; Cascieri, M.A. Linear amides as substance P antagonists. Bioorg. Med. Chem. Lett. 1996, 6, 1585-1588.

13. Ajaiyeoba, E.O.; Abiodun, O.O.; Falade, M.O.; Ogbole, N.O.; Ashidi, J.S.; Happi, C.T. In vitro cytotoxicity studies of 20 plants used in Nigerian antimalarial ethnomedicine. Phytomed. 2006, 13, 295-298. 
14. Santos Pimenta, L.P.; Pinto, G.B.; Takahashi, L.G.F. e Silva; Boaventura, M.A.D. Biological screening of Annonaceous Brazilian Medicinal Plants using Artemia salina (Brine Shrimp Test). Phytomedicine 2003, 10, 209-212.

15. Kapadia, G.J.; Azuine, M.A.; Tokuda, H.; Takasaki, M.; Mukainaka, T.; Konoshima, T.; Nishino, H. Chemopreventive effect of resveratrol, sesamol, sesame oil and sunflower oil in the EpsteinBarr virus early antigen activation assay and the mouse skin two-stage carcinogenesis. Pharm. Res. 2002, 45, 499-505.

16. Mongelli, E.; Desmarchelier, C.; Giulietti, A.; Coussio, J.; Ciccia, G. Bioactivity of certain medicinal latexes used by the Ese'ejas. J. Ethnopharm. 1995, 47, 159-163.

17. Badawey, E-SAM.; Kappe, T. Potential antineoplastics. Synthesis and cytotoxicity of certain 4chloro-3-(2-chloroethyl)-2-methylquinolines and related derivatives. Eur. J. Med. Chem. 1997, 32, 815-822.

18. Nick, A.; Rali, T.; Sticher, O. Biological screening of traditional medicinal plants from Papua New Guinea. J. Ethnopharm. 1995, 49, 147-156.

19. Wanyoike, G.N.; Chhabra, S.C.; Lang'at-Thoruwa, C.C.; Omar, S.A. Brine shrimp toxicity and antiplasmodial activity of five Kenyan medicinal plants. J. Ethnopharm. 2004, 90, 129-133.

20. McLaughlin, J.L.; Rogers, L.L.; Anderson, J.E. The Use of Biological Assays to Evaluate Botanicals. Drug Information Journal. 1998, 2, 513-524.

21. Miller, J.N.; Sampson, J.; Candeias, L.P.; Bramley, P.M.; Rice-Evans, C.A. Antioxidant activities of carotenes and xantophylls. FEBS Lett. 1996, 384, 240-242.

22. Miller, J.N.; Rice-Evans, C.A. Factors influencing the antioxidant activity determined by the ABTS+ radical cation assay. Free Rad. Res. 1997, 26, 195-199.

23. Miller, J.N.; Rice-Evans, C.A.; Davies, M.J.; Gopinathan, V.; Milner, A. A novel method for measuring antioxidant capacity and its application to monitoring the antioxidant status in premature neonates. Clin. Sci. 1993, 4, 407-412.

24. Hempel, S.L.; Buettner, G.R.; O’Malley, Y.Q.; Wessel, D.A.; Flaherty, D.M. Fluorescein diacetate is superior for detecting intracellular oxidants: comparison to $2^{\prime} 7^{\prime}$ dichlorodihydrofluorescein diacetate, 5(and 6)-carboxy-2'7'-dichlorodihydrofluorescein diacetate and dihydrorhodamine 123. Free Radic. Biol. Med. 1999, 27, 146-159.

25. Crow, J.P. Dichlorodihydrofluorescein and dihydrorhodamine 123 are sensitive indicators of peroxynitrite in vitro: implications for intracellular measurement of reactive nitrogen and oxygen species. Nitric Oxide 1997, 1, 145-157.

26. Mosmann, T.R. Rapid colorimetric assay for cellular growth and survival: application to proliferation and cytotoxicity assay. J. Immunol. Meth. 1983, 65, 55-63.

27. Green, L.M.; Reade, J.L.; Ware, C.F.R. Rapid colormetric assay for cell viability: Application to the quantitation of cytotoxic and growth inhibitory lymphokines. J. Immunol. Meth. 1984, 70, 257-268.

28. Opipari, A.W.jr.; Hu, H.M.; Yabkowitz, R.; Dixit, V.M. The A20 zinc finger protein protects cells from tumor necrosis factor cytotoxicity. J. Biol Chem. 1992, 267, 12424-12427.

29. Meyer, B.N.; Ferrigni, N.R.; Putnam, J.E.; Jacobsen, L.B.; Nichols, D.E.; McLaughlin, J.L. Brine shrimp: A convenient general bioassay for active plant constituents. Planta Med. 1982, 45, 31-34.

30. Finney, D.J. Probit Analysis. Cambridge University Press: Cambridge, U.K., 1971. 
31. Accelrys. Materials Studio 4.0. Accelrys, Inc. San Diego, CA, USA; www.accelrys.com

32. Perdew, J.P.; Wang, Y. Pair-distribution function and its coupling-constant average for the spinpolarized electron gas. Phys. Rev. B. 1992, 45, 13244.

33. Friedman, J. H. Multivariate adaptive regression splines. Anal. Stat. 1991, 19, 1-141.

Sample availability: Contact the authors.

(C) 2008 by MDPI (http://www.mdpi.org). Reproduction is permitted for noncommercial purposes. 